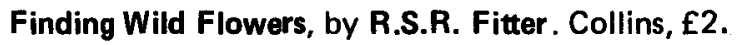

Described as a 'practical handbook to plant-hunting in Britain and a county-by-county guide' (also including the whole of Ireland), this is a truly remarkable publication - informative, admirably terse, of commendably high standard and providing a wealth of valuable detail.

Principally for the beginner and the amateur it concentrates on simplifying plant identification. The 9-page concise identification key, simple, explicit and reliable, is a masterpiece of ingenuity introducing a novel method of identifying plants from flower shapes and colour or leaf shapes. The inside boards skilfully display 33 small drawings, woodyplant leaf shapes and non-woody (or herbaceous) flower shapes in front, grasses, rushes, sedges, horsetails, waterweeds and ferns at the back - all needing little subsequent elaboration, though demanding considerable amplification. Thirty-two monochrome plates of striking clarity and beauty illustrate a variety of habitats showing examples of their prominent flora - what a joy to see a roadside verge still in floral glory - and depict 86 easily recognised flowers, two conspicuous grasses and a scarce fern.

The book is conveniently divided into three parts, each complementary; the first, a concise introduction to study of the flora; the second, the simplified practical identification key using leaf shape and eight categories of flower shape, which are further subdivided as necessary, and related to colour, together with reference to distribution; the third, a description of the various habitats, followed by a topographical guide to counties in alphabetical order, and indicating localities of special interest. Lists of learned and local societies and a brief bibliography are particularly helpful. A scientific index is followed by one with useful English equivalents.

Covering 'well over 2000 well-defined species of flowering plants', this is a worthy companion to McClintock and Fitter's 16-year old Pocket Guide to Wild Flowers - the reviewer's well-used botanical 'bible'. It will be enthusiastically welcomed by many and not only beginners, and at $f 2$ it is astonishingly inexpensive.

C.R.S. PITMAN

\title{
The Naturalist in Devon and Cornwall, by Roger Burrows. David \& Charles, $£ 3.50$.
}

This second volume in the Regional Naturalist series deals with a region which, while threatened in many ways, notably by the pressures of uncontrolled tourism, is still rich in relatively unspoilt country, particularly along the coast and on the moors. Roger Burrows treats it as a single unit with chapters on all the major habitats: woodlands, moorland, seashore, sand dunes, cliffs, estuaries and so on. He reviews each in turn, relating the vegetation cover to the geological background and describing the more obvious and important forms of animal life both vertebrate and invertebrate. Conservation problems - such as the disposal of china clay waste and the need for marine reserves - are fully emphasised and the result is an extremely well balanced book. Excellent maps and diagrams are used to explain such diverse aspects of the natural history as, for example, the distribution of habitats and species along a Dartmoor stream, vegetation zones on the cliffs, and the distribution of fish off the south coast and of birds on Exmoor. There are thirty well selected photographs and a series of appendices listing 